\title{
Axial-Ligand-Cleavable Silicon Phthalocyanines Triggered by Near-Infrared Light toward Design of Photosensitizers for Photoimmunotherapy
}

Hideo Takakura

Hokkaido Univeristy

Shino Matsuhiro

Hokkaido Univeristy

Masato Kobayashi

Hokkaido University

Yuto Goto

Hokkaido University

Mei Harada

Hokkaido University

Tetsuya Taketsugu

Hokkaido University

Mikako Ogawa ( $\nabla$ mogawa@pharm.hokudai.ac.jp )

Hokkaido University

\section{Article}

Keywords: Near-infrared photoimmunotherapy (NIR-PIT), IRDye700DX (IR700), silicon phthalocyanine (SiPc), near-infrared (NIR), HER2

Posted Date: September 20th, 2021

DOl: https://doi.org/10.21203/rs.3.rs-904362/v1

License: (a) (1) This work is licensed under a Creative Commons Attribution 4.0 International License. Read Full License

Version of Record: A version of this preprint was published at Journal of Photochemistry and Photobiology A: Chemistry on December 1st, 2021. See the published version at https://doi.org/10.1016/j.jphotochem.2021.113749. 
1 Axial-Ligand-Cleavable Silicon Phthalocyanines Triggered by Near-Infrared Light

2 toward Design of Photosensitizers for Photoimmunotherapy

3 Hideo Takakura ${ }^{1}$, Shino Matsuhiro ${ }^{1}$, Masato Kobayashi ${ }^{2,3}$, Yuto Goto ${ }^{1}$, Mei Harada ${ }^{1}$,

4 Tetsuya Taketsugu ${ }^{2,3}$, Mikako Ogawa*1

5

$6 \quad{ }^{1}$ Laboratory of Bioanalysis and Molecular Imaging, Graduate School of Pharmaceutical

7 Sciences, Hokkaido University, Sapporo, Hokkaido, Japan

$8 \quad{ }^{2}$ Faculty of Science, Hokkaido University, Sapporo, Hokkaido, Japan

$9 \quad{ }^{3}$ WPI-ICReDD, Hokkaido University, Sapporo, Hokkaido, Japan

$11 *$ Corresponding author: Mikako Ogawa

12 Laboratory of Bioanalysis and Molecular Imaging, Graduate School of Pharmaceutical

13 Sciences, Hokkaido University, Sapporo, Hokkaido 060-0812, Japan

14 Phone: +81-11-706-3767, Fax: +81-11-706-3767.

$15 \quad$ E-mail: mogawa@pharm.hokudai.ac.jp 


\section{Abstract}

Near-infrared photoimmunotherapy (NIR-PIT) is a novel phototherapy for the treatment of cancer that uses NIR light and conjugates of antibody-IR700, a silicon phthalocyanine photosensitizer. A key feature of NIR-PIT is light-induced axial ligand cleavage of IR700, which finally causes cytotoxicity. Here, we focused on protonation of the axial ligand on the IR700 anion radical during the photochemical process. The Gibbs energy in the protonation reaction of IR700 derivatives with different axial ligands was calculated. These calculations suggested the order of the cleavage efficiency corresponds to the basicity of the axial ligand (i.e. alkoxy $>$ siloxy $($ IR700) $>$ phenoxy $\approx$ oxycarbonyl), which was confirmed by the photoirradiation experiments with synthesized compounds. Thus, axial ligand cleavage is significantly dependent on the basicity of the axial ligand. Our findings suggest that PIT reagent with an IR700 derivative bearing alkoxy group would show better efficacy than IR700.

\section{Introduction}

IRDye 700DX (IR700) is a silicon phthalocyanine ( $\mathrm{SiPc}$ ) derivative that absorbs near-infrared (NIR) light and has been used not only as a fluorescent imaging reagent but also as a photosensitizer for NIR photoimmunotherapy (NIR-PIT) (Fig. 1a). ${ }^{1,2}$ In NIR- 
37 PIT, IR700-antibody conjugate and NIR light are used to treat cancer. Because the cytotoxicity is induced only when the conjugate is bound to the cell membrane and irradiated with NIR light, NIR-PIT can specifically kill cancer cells. To date, various cancer antigens, such as epidermal growth factor receptor (EGFR) and human epidermal growth factor receptor 2 (HER2), have been targeted. In pre-clinical experiments, NIRPIT has shown efficacy against gastric, ${ }^{3,4}$ lung, ${ }^{5}$ prostate,${ }^{6}$ and breast $^{7}$ cancers. In addition, successful first-in-human phase I and II studies in patients with unresectable locally advanced head and neck cancer were completed (NCT02422979). More recently, Cetuximab-IR700, a PIT conjugate for EGFR, was approved in Japan. These studies suggest PIT will be a valuable new form of cancer treatment. Because light is attenuated by tissue absorption and scattering, PIT utilizes NIR light delivered through a thin fiber, such as a catheter or needle, to increase the efficiency of light delivery at deep sites. Moreover, cytotoxicity should be further enhanced by using

50 a light-sensitive photosensitizer that is more responsive to NIR light. However, only IR700 has been reported as a photosensitizer for PIT. Therefore, it remains unclear whether IR700 is the optimal photosensitizer for this treatment. Recently, the mechanism of cytotoxicity in PIT has been investigated both experimentally and theoretically. As

54 shown in Fig. 1b, IR700 is excited to the singlet excited state by NIR light, and then 
transitions to the triplet state via intersystem crossing (ISC). However, the quantum yield of ISC is not high $\left(\Phi_{I S C}=0.019\right) .{ }^{8}$ IR700 in the triplet state receives electrons from electron donors to form the anion radical. Next, the anion radical is protonated by a hydronium ion, followed by axial ligand cleavage and the coordination of a hydroxy ion, which occur spontaneously at room temperature due to the lower activation energy of the photochemical process $\left(\mathrm{E}^{\ddagger}<92.4 \mathrm{~kJ} \mathrm{~mol}^{-1}\right) .{ }^{9,10}$ The photodegraded compound loses its hydrophilic functional moiety (i.e. six sulfonate groups in all), which drastically changes its physicochemical properties from water-soluble to insoluble. As a result, the conjugate aggregates on the cell membrane, leading to physical damage and ultimately cell death. ${ }^{11,12}$ Thus, axial ligand cleavage of the photosensitizer is a crucial step in PIT. The development of a light-sensitive photosensitizer involves the design of SiPcs in which the axial ligand is more readily cleaved by NIR light. cleavage by NIR light is dependent on the $\mathrm{pH}$ of the solution. ${ }^{9}$ At higher $\mathrm{pH}$, light-induced cleavage of the axial ligand was inhibited because protonation of the SiPc anion radical did not occur. These results suggested that axial ligand cleavage is dependent on the basicity of axial ligand. Thus, in order to develop an SiPc derivative that is more lightsensitive than IR700, we focused on the basicity of the axial ligands. Here, the basicity 
73 of SiPcs with various axial ligands was estimated by performing quantum chemical

74 calculations. The compounds were then synthesized, and light-induced axial ligand

75 cleavage was compared.

$77 \quad$ Results and discussions

Quantum chemical calculations of SiPcs with different axial ligands in photoinduced

axial ligand cleavage. We reported that in the presence of an electron donor under hypoxic conditions, the axial ligand of the IR700 derivative cleaves at $\mathrm{pH} 7.0$, while at

$81 \mathrm{pH} 11.0$ no cleavage of the axial ligand occurs despite the generation of an anion radical. ${ }^{9}$

82 This result motivated us to investigate the reactivity of SiPcs having other axial ligands

83 with a different basicity. Rather than a siloxy group as the axial ligand, we chose alkoxy, oxycarbonyl and phenoxy groups because they show a different basicity and are functional groups capable of forming an Si-O bond (Fig. 2a). As in our previous study, symmetric SiPc derivatives were used as model compounds for the calculations (compounds 1'-4', Fig. 2b). ${ }^{9}$ Density functional theory (DFT) calculations were performed to determine the change in Gibbs energy $(\Delta G)$ of each compound (1'-4') for the following protonation reaction of the axial ligand at $298.15 \mathrm{~K}$ :

90

$$
\left[\mathrm{SiPcY}_{2}\right]^{\cdot-}+\mathrm{H}_{3} \mathrm{O}^{+} \rightarrow\left[\mathrm{SiPc}(\mathrm{YH}) \mathrm{Y}^{\bullet}+\mathrm{H}_{2} \mathrm{O}\right.
$$




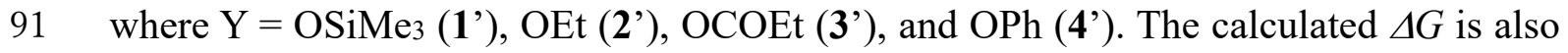

92 summarized in Fig. 2b. As for the oxycarbonyl axial ligand, protonation of the carbonyl

93 oxygen was considered because it is more basic than the ester oxygen. All $\Delta G$ values are

94 negative, indicating that the reaction (1) is exergonic. The order of $\Delta G$ for each compound

95 was compound 2' (alkoxy) < compound 1' (siloxy) < compound 4' (phenoxy) $\approx$

96 compound 3' (oxycarbonyl). If we assume equilibration between the anion radical form

$97\left(\left[\mathrm{SiPcY}_{2}\right]^{{ }^{-}}\right)$and the protonated form $\left(\left[\mathrm{SiPc}(\mathrm{YH}) \mathrm{Y}^{\circ}\right]^{\circ}\right)$ in solution, these results suggest the

98 protonated form of the alkoxy ligand is favored over the other ligands and has more

99 opportunity to proceed with the ligand cleavage reaction. However, the result differs from

100 a previous report that investigated SiPcs having an asymmetric axial ligand, alkoxy and

101 phenoxy groups. ${ }^{13}$ The previous study concluded that the axial ligand of a phenoxy group

102 cleaves more readily upon NIR light irradiation than an alkoxy group. This apparent

103 discrepancy might arise because (i) the concerted hydrolysis reaction pathway has an

104 activation energy of approximately $30 \mathrm{~kJ} \mathrm{~mol}^{-1}$ higher than the stepwise pathways

105 considered in this study, and (ii) symmetrical differences in the axial ligand (i.e.

106 symmetric versus asymmetric). Our results suggest the anticipated efficiency of axial

107 ligand cleavage to be: compound $\mathbf{2}>$ compound $\mathbf{1}>$ compound $\mathbf{4} \approx$ compound $\mathbf{3}$. The

108 detailed energy diagram for the formation of $\left[\mathrm{SiPc}(\mathrm{OH}) \mathrm{Y}^{--}\right.$from $\left[\mathrm{SiPcY}_{2}\right]^{{ }^{--}}$in neutral 
water solution (summarized in our previous report for the case of $\mathrm{Y}=\mathrm{OSiMe}_{3}$ ) is shown in supporting information (see Supplementary Fig. 1).

113 Given the above results, we synthesized compounds 2-4 (Fig. 2a) to experimentally

114 evaluate the predictions based on the theoretical calculations. As shown in Figure 3, the

115 axial ligands were conjugated via SiPc dichloride (6) using sodium hydride or $\mathrm{K}_{2} \mathrm{CO}_{3}$ as

116 a base. Final products containing a water-soluble group at the end of the axial ligand were

117 synthesized in $\mathrm{MeOH}$ with sultone. Compounds 2-4 were characterized by ${ }^{1} \mathrm{H}$ NMR and

118 MS. To investigate whether the axial ligands of SiPc affect their photochemical properties,

119 we measured the absorption/emission spectra and determined the fluorescence quantum

120 yields $\left(\Phi_{F L}\right)$ and the molar extinction coefficients $(\varepsilon)$. All the compounds showed almost

121 identical photochemical properties (see Supplementary Fig. 2 and Table 1). Compounds

122 1-4 displayed similar shaped absorption and emission spectra with a sharp Q-band

123 absorption peak in the range of 677-691 $\mathrm{nm}$ and a sharp emission peak in the range of

$124 \quad 684-699 \mathrm{~nm}$. The relative $\Phi_{F L}$ of compounds 2-4 were calculated with reference to the

125 absolute $\Phi_{F L}$ of compound $\mathbf{1}\left(\Phi_{F L}=0.31\right){ }^{8}$ As a result, $\Phi_{F L}$ of compounds 2-4 were 0.30,

1260.27 and 0.29 , respectively. Furthermore, $\varepsilon$ at the Q-band of compounds 1-4 in water were 
127 1.7-1.9 $\times 10^{5} \mathrm{~L} \mathrm{~mol}^{-1} \mathrm{~cm}^{-1}$. These results indicate the axial ligands do not significantly

128 affect the photochemical properties of the SiPc derivatives.

Comparison of photoinduced axial ligand cleavage reaction of synthesized SiPcs.

131 With these compounds in hand, we investigated the axial ligand photocleavage of compounds 1-4. The compounds in a phosphate buffer with dithiothreitol (DTT) as an

133 electron donor were irradiated with an NIR laser $(690 \mathrm{~nm})$ at different light doses. After irradiation, the solutions were analyzed by HPLC with methylene blue as an internal standard. NIR light irradiation of compounds 1-4 caused the peaks of the original compound to decrease and other peaks to appear (Fig. 4a-d). Indeed, as the light dose increased, the peaks of the original compounds disappeared. The degradation products of compound $\mathbf{1}$, named degrade $1 \mathrm{a}$ and $1 \mathrm{~b}$, were previously identified as SiPc with one or both $\left(\mathrm{SiPc}(\mathrm{OH})_{2}\right)$ of the axial ligands cleaved, respectively (Fig. 4e). ${ }^{10}$ The other

140 degradation products, degrade $2 \mathrm{~b}, 3 \mathrm{a}$ and $4 \mathrm{a}$, were also analyzed by double injection with authentic compound $\mathrm{SiPc}(\mathrm{OH})_{2}$. In each case the degradation product was identified as

$142 \mathrm{SiPc}(\mathrm{OH}) 2$, as with compound 1 (see Supplementary Fig. 3). Based on these findings, degrade $2 \mathrm{a}$ was expected to be SiPc with uniaxial ligand. Thus, we synthetically prepared

144 the compound (compound 2-half) from compound 2 (Fig. 4e and see Supplementary 
145 Scheme 1). Using the authentic compound, degrade 2a was identified as compound 2-half

146 (see Supplementary Fig. 3). In the case of no NIR irradiation, compounds 1-4 did not

147 degrade at all (see supplementary Fig. 4). These results show that the axial ligands of

148 compounds 2-4 are cleaved by NIR irradiation in the presence of an electron donor, as in

149 compound 1.

$151 \mathbf{1}$ and 2, peaks corresponding to SiPc with uniaxial ligand (degrades 1a, 2a) was observed,

152 which disappeared upon increasing light dose together with a concomitant increase in the

153 appearance of $\operatorname{SiPc}(\mathrm{OH})_{2}$ (degrades 1b, 2b) (Fig. 4a,b). By contrast, for compounds 3 and

1544 , light irradiation resulted in the formation of $\operatorname{SiPc}(\mathrm{OH})_{2}$ (degrades $\left.3 \mathrm{a}, 4 \mathrm{a}\right)$, but no peaks

155 corresponding to SiPc with uniaxial ligand (Fig. 4c,d). When compounds 3 and 4 were

156 hydrolyzed in aqueous solution at pH11-12, peaks of compounds 3 and $\mathbf{4}$ with uniaxial

157 ligand were not detected but that of $\mathrm{SiPc}(\mathrm{OH})_{2}$ was detected (see Supplementary Fig. 5).

158 On the other hand, in the hydrolysis of compounds $\mathbf{1}$ and $\mathbf{2}$, peaks of compounds $\mathbf{1}$ and $\mathbf{2}$

159 with uniaxial ligand were detected. These results suggest compounds $\mathbf{3}$ and $\mathbf{4}$ with

160 uniaxial ligand might be unstable in aqueous solution. Another possibility is that in the

161 case of compounds $\mathbf{3}$ and $\mathbf{4}$, the two axial ligands were sequentially cleaved in the

162 photochemical reaction, whereas cleavage of the axial ligand of compounds $\mathbf{1}$ and $\mathbf{2}$ 
163 occurred one by one. Thus, the change in $\Delta G$ for the protonation reaction to the second 164 axial ligand, namely,

$$
\left[\mathrm{SiPc}(\mathrm{OH}) \mathrm{Y}^{\cdot-}+\mathrm{H}_{3} \mathrm{O}^{+} \rightarrow[\mathrm{SiPc}(\mathrm{YH})(\mathrm{OH})]^{\bullet}+\mathrm{H}_{2} \mathrm{O}\right.
$$

167 Fig. 2(b) shows the $\Delta G$ of eq (2) for oxycarbonyl and phenoxy ligands are 7.8 and $0.3 \mathrm{~kJ}$

$168 \mathrm{~mol}^{-1}$ lower than those of eq (1), respectively. By contrast, the $\Delta G$ of eq (2) for siloxy and

169 alkoxy ligands are 4.5 and $4.6 \mathrm{~kJ} \mathrm{~mol}^{-1}$ higher than eq (1), respectively. This observation supports the sequential cleavage of compounds 3 and 4 .

compounds 1-4. Because $\mathrm{SiPc}(\mathrm{OH})_{2}$ is hydrophobic with limited solubility in aqueous solution, most of the reaction product precipitated. Thus, although the dissolved portion of $\mathrm{SiPc}(\mathrm{OH})_{2}$ was detected by HPLC, we could not quantify axial ligand cleavage from the peak areas of $\operatorname{SiPc}(\mathrm{OH})_{2}$. Therefore, comparison of the reaction efficiency was performed from the decrease in the peak areas of compounds 1-4. As anticipated from the theoretical calculations, the order of efficiency was compound $\mathbf{2}>$ compound $\mathbf{1}>$ compound $4 \approx$ compound 3 , consistent with the order of $\Delta G$ of the anion radicals upon protonation (Fig. 4f). These results show that the $\Delta G$ value correlated with the efficiency of axial ligand cleavage. Specifically, the basicity of the axial ligand was related to the 
181 dissociation efficiency. Thus, we successfully developed compound $\mathbf{2}$ with an axial ligand comprising an alkoxy group that is more light-sensitive than compound $\mathbf{1}$.

184 ligand cleavage depended on the electron donor. ${ }^{14}$ Thus, we used a variety of electron 185 donors and compared the axial ligand cleavage of compounds $\mathbf{1 - 4}$ by NIR light in the 186 presence of these donors (see Supplementary Table 1$)$. In addition to DTT (Ered $=-0.33$

$187 \mathrm{~V}),{ }^{15,16}$ we used nicotinamide adenine dinucleotide $(\mathrm{NADH}$, Ered $=-0.32 \mathrm{~V}),{ }^{17,18}$ cysteine 188 (Cys, Ered $=-0.20--0.23 \mathrm{~V}),{ }^{16,19}$ glutathione $(\mathrm{GSH}, \text { Ered }=-0.20--0.26 \mathrm{~V})^{16,19,20}$ and 189 sodium ascorbate $\left(\mathrm{NaAA}, \mathrm{E}_{\mathrm{red}}=0.35-0.39 \mathrm{~V}\right) .^{21,22}$ As a result, the efficiencies of axial 190 ligand cleavage varied, and was independent of the redox potential and the structure of 191 the electron donating group (see Supplementary Fig. 7). For example, although GSH and 192 Cys have similar redox potentials and the same functional group for electron donation, axial ligands of compounds $\mathbf{3}$ and $\mathbf{4}$ were efficiently cleaved in the presence of Cys, but not GSH. Nonetheless, the efficiency of the axial ligand cleavage for each electron donor was in the order of the basicity of the axial ligand. Hence, basicity had a significant effect on light-induced axial ligand cleavage.

Discussion about development of new PIT reagents. In NIR-PIT, it is thought that 
aggregation of the conjugates, which causes physical damage to the cell membrane, is

200 induced by axial ligand cleavage of the photosensitizer. Here, we performed theoretical

201 calculations and experiments that show the basicity of the axial ligand is involved in

202 efficiency of the cleavage. Moreover, axial ligand cleavage of compound 2 was more

203 light-responsive than that of compound $\mathbf{1}$. Therefore, compound $\mathbf{2}$ having a linker for

204 conjugation with an antibody should be a better photosensitizer than IR700. Moreover,

205 based on the results of this study, an even better photosensitizer could be developed by

206 modifying the axial ligand. Thus, our analysis provides useful guidelines that will assist

207 in the development of improved photosensitizers for PIT.

\section{Conclusions}

Herein, we examined the photoinduced ligand release of IR700 derivatives with

211 different axial ligands, such as alkoxy, siloxy, oxycarbonyl and phenoxy groups.

212 Theoretical and experimental investigations revealed the order of basicity of the axial

213 ligands coincided with the order of efficiency of photoinduced axial ligand cleavage.

214 These results indicate that axial ligand cleavage is significantly influenced by protonation

215 of the axial ligand of the anion radical. Based on the results of this study it should also be

216 possible to design a compound whose axial ligand is cleaved with high reactivity to light. 
217 Thus, novel PIT reagents with improved properties will be developed in the near future.

219 Materials and methods

220 Reagents and general information. General chemicals were of the best grade available,

221 supplied by FUJIFILM Wako Pure Chemical Corporation (Osaka, Japan), Tokyo

222 Chemical Industries Co., Ltd (Tokyo, Japan), Sigma-Aldrich Co. LLC (St. Louis, MO,

223 USA) and KANTO CHEMICAL Co., INC. (Tokyo, Japan), and were used without further

224 purification. NMR spectra were recorded on a JNM-ECX400P or JMN-ECS400 (JEOL

225 Ltd., Tokyo, Japan) instrument at $400 \mathrm{MHz}$ for ${ }^{1} \mathrm{H}$ NMR. $\delta$ values are given in ppm

226 relative to tetramethylsilane or deuterated solvent signals. ESI and MALDI-TOF mass

227 spectra (MS) were measured with a JMS-T100LP (JEOL Ltd.) and an Ultraflex II

228 TOF/TOF (Bruker Corporation, Billerica, MA, USA), respectively. High performance

229 liquid chromatography (HPLC) analyses and purification were performed using an HPLC

230 system (Shimadzu Corporation, Kyoto, Japan) with reverse-phase columns, Inertsil ODS-

$2313(4.6 \mathrm{~mm} \times 150 \mathrm{~mm}$ for analysis, $10 \mathrm{~mm} \times 150 \mathrm{~mm}$ for purification) (GL Sciences Inc.,

232 Tokyo, Japan), with eluent A (0.1 M triethylammonium acetic acid (TEAA)) and eluent

B $\left(99 \% \mathrm{CH}_{3} \mathrm{CN} / 1 \% \mathrm{H}_{2} \mathrm{O}\right)$. 
236 Compound 1 and $\operatorname{SiPc}(\mathrm{OH})_{2}$ were synthesized according to literature reports. ${ }^{10}$

237 Silicon Phthalocyanine Dichloride (6). The compound was synthesized according to a

238 protocol described in the literature. ${ }^{23}$ Briefly, 1,3-diiminoisoindoline 5 (176 mg, 1.2

$239 \mathrm{mmol})$ and silicon tetrachloride $(300 \mathrm{mg}, 1.8 \mathrm{mmol})$ were dissolved in quinoline $(2 \mathrm{~mL})$,

240 and the mixture was refluxed for $2 \mathrm{~h}$ under an $\mathrm{Ar}$ atmosphere. After cooling to room

241 temperature, $\mathrm{MeOH}$ was added to the reaction mixture. The precipitate was collected by

242 filtration, washed with $\mathrm{MeOH}$, and dried in vacuo. The green-blue crude product was

243 obtained and used for the next synthesis without further purification (123 mg).

244 Bis(4-aminobutyloxide) Silicon Phthalocyanine (7). Crude compound 6 (50 mg, ca.

$2450.082 \mathrm{mmol}), 4$-aminobutanol $(73 \mathrm{mg}, 0.82 \mathrm{mmol})$, and sodium hydride $(39 \mathrm{mg}, 1.6$

$246 \mathrm{mmol})$ were dissolved in toluene $(40 \mathrm{~mL})$ and the mixture was refluxed for $8 \mathrm{~h}$ under an

247 Ar atmosphere. After cooling to room temperature, the reaction mixture was evaporated

248 below $35^{\circ} \mathrm{C}$. The residue was suspended with $\mathrm{H}_{2} \mathrm{O}-\mathrm{EtOH}$ solution $(2: 1)$, collected by

249 filtration, washed with $\mathrm{H}_{2} \mathrm{O}-\mathrm{EtOH}$ solution (2:1), and dried in vacuo. A blue product was

250 obtained (31 mg, $0.043 \mathrm{mmol}, 52 \%$ (2 steps)). ${ }^{1} \mathrm{H}$ NMR (400 MHz, $\left.\mathrm{CDCl}_{3}\right): \delta-2.10(\mathrm{t}, J$

$251=6.1 \mathrm{~Hz}, 4 \mathrm{H}),-1.64(\mathrm{tt}, J=6.1,7.2 \mathrm{~Hz}, 4 \mathrm{H}),-1.25(\mathrm{tt}, J=7.2,7.2 \mathrm{~Hz}, 4 \mathrm{H}), 0.94(\mathrm{t}, J$

$\left.252=7.2 \mathrm{~Hz}, 4 \mathrm{H}), 8.34(\mathrm{dd}, J=2.9,5.6 \mathrm{~Hz}, 8 \mathrm{H}), 9.64(\mathrm{dd}, J=2.9,5.6 \mathrm{~Hz}, 8 \mathrm{H}) . \mathrm{HRMS}_{(\mathrm{ESI}}^{+}\right)$ 
$253 \mathrm{~m} / \mathrm{z}$ : calcd for $\mathrm{C}_{40} \mathrm{H}_{38} \mathrm{~N}_{10} \mathrm{O}_{2} \mathrm{Si}: 359.1470[\mathrm{M}+2 \mathrm{H}]^{2+}$; found: 359.1469 .

254 Bis [(6-aminohexanoyl)oxide] Silicon Phthalocyanine (8). Crude compound 6 (300 mg,

255 ca. $0.49 \mathrm{mmol}$ ), 6-aminohexanoic acid (640 mg, $4.9 \mathrm{mmol})$, and $\mathrm{K}_{2} \mathrm{CO}_{3}$ (200 mg, 1.5

$256 \mathrm{mmol})$ were dissolved in toluene $(20 \mathrm{~mL})$ and the mixture was refluxed for $21 \mathrm{~h}$ under an

257 Ar atmosphere. After cooling to room temperature, the reaction mixture was evaporated

258 below $35^{\circ} \mathrm{C}$. The residue was suspended in $\mathrm{CH}_{2} \mathrm{Cl}_{2}$, collected by filtration, washed with

$259 \mathrm{CH}_{2} \mathrm{Cl}_{2}$, and dried in vacuo. A blue product was obtained (76 mg, $0.094 \mathrm{mmol}, 14 \%$ (2

260 steps)). ${ }^{1} \mathrm{H}$ NMR (400 MHz, $\left.\mathrm{CDCl}_{3}\right): \delta-0.92--0.89(\mathrm{~m}, 4 \mathrm{H}),-0.79--0.71(\mathrm{~m}, 4 \mathrm{H})$,

$261-0.64--0.62(\mathrm{~m}, 4 \mathrm{H}), 0.15-0.23(\mathrm{~m}, 4 \mathrm{H}), 1.94(\mathrm{t}, J=6.9 \mathrm{~Hz}, 4 \mathrm{H}), 8.39$ (dd, $J=2.7,5.7$

$262 \mathrm{~Hz}, 8 \mathrm{H}), 9.70(\mathrm{dd}, J=2.7,5.7 \mathrm{~Hz}, 8 \mathrm{H})$. HRMS $\left(\mathrm{ESI}^{+}\right) \mathrm{m} / \mathrm{z}$ : calcd for $\mathrm{C}_{44} \mathrm{H}_{42} \mathrm{~N}_{10} \mathrm{O}_{4} \mathrm{Si}_{\text {: }}$

$263401.1574[\mathrm{M}+2 \mathrm{H}]^{2+}$; found: 401.1574.

264 Bis(4-aminomethylphenoxide) Silicon Phthalocyanine (9). The compound was

265 synthesized using the same method as described for compound 7. 4-

266 (Aminomethyl)phenol was used as the reagent for the axial ligand. The product was used

267 for the next synthesis without further purification.

268 General procedure for alkylsulfonation. Silicon phthalocyanine with two axial ligands

269 (30-75 mg, 0.042-0.094 mmol), 1,3-propanesultone $(23-25$ eq) and $N, N-$

270 diisopropylethylamine (DIEA, 46-50 eq) were dissolved in $\mathrm{MeOH}(4 \mathrm{~mL})$, and the 
271 mixture was stirred at $50{ }^{\circ} \mathrm{C}$ for $72 \mathrm{~h}$ under an $\mathrm{Ar}$ atmosphere. The product was purified

272 by HPLC (eluent $\mathrm{A} /$ eluent $\mathrm{B}=80 / 20$ to $50 / 50$ in $15 \mathrm{~min}, 50 / 50$ to $0 / 100$ in $5 \mathrm{~min}$ ). The 273 product was then desalted with a Sep-Pak C18 cartridge (Waters Corp., Milford, MA, 274 USA) and cation-exchange resin.

275 Bis $\{4-[\operatorname{tris}(3-$-sulfopropyl)]ammoniobutyloxide\} Silicon Phthalocyanine (2). The 276 reaction yield was $20 \% .{ }^{1} \mathrm{H}$ NMR $\left(400 \mathrm{MHz}, \mathrm{CD}_{3} \mathrm{OD}\right): \delta-1.93(\mathrm{t}, J=6.1 \mathrm{~Hz}, 4 \mathrm{H}),-1.46-$ $277-1.37(\mathrm{~m}, 4 \mathrm{H}),-1.01--0.91(\mathrm{~m}, 4 \mathrm{H}), 1.32-1.50(\mathrm{~m}, 16 \mathrm{H}), 2.53-2.64(\mathrm{~m}, 24 \mathrm{H}), 8.53(\mathrm{dd}$, $278 J=2.9,5.7 \mathrm{~Hz}, 8 \mathrm{H}), 9.79(\mathrm{dd}, J=2.9,5.6 \mathrm{~Hz}, 8 \mathrm{H}) . \mathrm{HRMS}\left(\mathrm{ESI}^{-}\right): \mathrm{m} / \mathrm{z}$ calcd for $279 \mathrm{C}_{58} \mathrm{H}_{68} \mathrm{~N}_{10} \mathrm{Na}_{3} \mathrm{O}_{20} \mathrm{~S}_{6} \mathrm{Si}: 1513.2403[\mathrm{M}-\mathrm{Na}]^{-}$; found: 1513.2417.

Bis(\{6-[tris(3-sulfopropyl)]ammoniohexanoyl\}oxide) Silicon Phthalocyanine (3). The

reaction yield was 20\%. ${ }^{1} \mathrm{H}$ NMR $\left(400 \mathrm{MHz}, \mathrm{CD}_{3} \mathrm{OD}\right): \delta-0.69--0.66(\mathrm{~m}, 8 \mathrm{H}),-0.57-$ $-0.54(\mathrm{~m}, 4 \mathrm{H}), 0.63-0.66(\mathrm{~m}, 4 \mathrm{H}), 1.88-1.91(\mathrm{~m}, 12 \mathrm{H}), 2.36-2.38(\mathrm{~m}, 4 \mathrm{H}), 2.78(\mathrm{t}, J=6.3$ $\mathrm{Hz}, 12 \mathrm{H}), 3.13-3.18(\mathrm{~m}, 12 \mathrm{H}), 8.57(\mathrm{dd}, J=3.0,6.0 \mathrm{~Hz}, 8 \mathrm{H}), 9.80(\mathrm{dd}, J=3.0,6.0 \mathrm{~Hz}$, 8H). HRMS (ESI $\left.{ }^{-}\right): \mathrm{m} / \mathrm{z}$ calcd for $\mathrm{C}_{62} \mathrm{H}_{72} \mathrm{~N}_{10} \mathrm{Na}_{3} \mathrm{O}_{22} \mathrm{~S}_{6} \mathrm{Si}: 1597.2615[\mathrm{M}-\mathrm{Na}]^{-}$; found: 1597.2615.

Bis $\{4$-[tris(3-sulfopropyl)]ammoniomethylphenoxide\} Silicon Phthalocyanine (4). 

and a spectrofluorometer FP-8600 (JASCO Corporation, Tokyo, Japan), respectively. The relative fluorescence quantum yield $\left(\Phi_{\mathrm{FL}}\right)$ was obtained with the following equation:

$$
\Phi_{F L}^{\text {sample }}=\Phi_{F L}^{\text {standard }} \times \frac{F^{\text {sample }}}{F^{\text {standard }}} \times\left(\frac{n^{\text {sample }}}{n^{\text {standard }}}\right)^{2} \times \frac{A b s^{\text {standard }}}{A b s^{\text {sample }}}
$$

$F$ denotes the area under the fluorescence band $\left(F=\Sigma I_{\mathrm{FL}}(\lambda)\right.$, where $I_{\mathrm{FL}}(\lambda)$ is the as a reference $\left(\Phi_{\mathrm{FL}}=0.31\right)$ of the fluorescence quantum yield.

NIR photolysis of phthalocyanine derivatives. A solution of $5 \mu \mathrm{M}$ phthalocyanine derivatives in sodium phosphate buffer ( $\mathrm{pH}$ 7.0) containing $1 \mathrm{mM}$ DTT was prepared in a vial. The solution was bubbled with Ar through the septum cap of the sealed vial before 
307 Technology Co., Ltd, Changchun, China) $\left(690 \mathrm{~nm}, 40 \mathrm{~mW} \mathrm{~cm}^{-2}\right)$ for 3-20 min (7.2-48 J

$308 \mathrm{~cm}^{-2}$ ). The irradiated solution was analyzed by HPLC (eluent A/eluent $\mathrm{B}=75 / 25$ to $60 / 40$

309 in $5 \mathrm{~min}, 60 / 40$ to $0 / 100$ in 10 min for compound 2, eluent $\mathrm{A} / \mathrm{eluent} \mathrm{B}=80 / 20$ to $0 / 100$

310 in $10 \mathrm{~min}$ for compounds $\mathbf{1 , 3}$ and 4). The detection wavelength was $670 \mathrm{~nm}$. Methylene

311 blue (MB) was used as an internal standard. The power densities were measured with an

312 optical power meter PM200 (Thorlabs Inc., Newton, NJ, USA). All the experiments were

313 carried out at room temperature.

315 Computational details. DFT calculations were performed for the silicon phthalocyanine

316 model compounds, 1'-4', and their protonated forms using Gaussian 16 . $^{24}$ The LC-BLYP

317 functional, ${ }^{25}$ which combines the long-range corrected Becke exchange functional ${ }^{26}$ and

318 the Lee-Yang-Parr correlation functional ${ }^{27}$ was employed. Spin-unrestricted Kohn-Sham

319 self-consistent field calculations were also performed. The aug-cc-pVDZ basis set ${ }^{28}$ was

320 utilized for $\mathrm{N}$ and $\mathrm{O}$ atoms, while the cc-pVDZ basis $\operatorname{set}^{29,30}$ was adopted for the other

321 atoms. The water solvent effect was incorporated using the integral equation formalism

322 variant of the polarizable continuum model (IEFPCM). ${ }^{31}$ All geometries were optimized

323 at the same level of theory and normal mode analysis was performed at the optimized

324 structures to obtain the thermally corrected Gibbs energy at $298.15 \mathrm{~K}$ and $1 \mathrm{~atm}$. 
Data availability

327 The data that support the findings of this study are available from the corresponding 328 author upon reasonable request.

\section{Acknowledgement} This work was supported by JST-PRESTO (Grant Number: JPMJPR15P5 to M.O.), JST-CREST (Grant Number: JPMJCR1902 to M.O.) and the JSPS KAKENHI (Grant Number: JP19H03593 to M.O.), the Photo-excitonix Project in Hokkaido

334 University, and by The Nakajima Foundation (grant to H.T.). The Institute for Chemical Reaction Design and Discovery (ICReDD) was established by the World Premier

International Research Initiative (WPI), MEXT, Japan. Some calculations were performed using the computer facilities at Research Center for Computational Science,

338 Okazaki and at Research Institute for Information Technology, Kyushu University, Japan.

\section{Author contributions}

342 the experiments, collected and analyzed the data. M.K., M.H. and T.T. performed 
343 computational calculations. H.T. and M. K. wrote the paper and all authors contributed to

344 manuscript revision and approved the final version.

345

346 Competing interests

347

M.O. has received research grants and consultation fees from Rakuten Medical,

348 Inc.

349

350

Additional information

351

Supplementary information The online version contains supplementary material

352 available.

353

Correspondence and requests for materials should be addressed to M.O.

354 


\section{References}

356

357

358

359

360

361

362

363

364

365

366

367

368

369

370

371

372

1. Mitsunaga, M. et al. Cancer cell-selective in vivo near infrared photoimmunotherapy targeting specific membrane molecules. Nat. Med. 17, 1685-1691 (2011).

2. Kobayashi, H. \& Choyke, P. L. Near-Infrared Photoimmunotherapy of Cancer. Acc. Chem. Res. 52, 2332-2339 (2019).

3. Shirasu, N., Yamada, H., Shibaguchi, H., Kuroki, M. \& Kuroki, M. Potent and specific antitumor effect of CEA-targeted photoimmunotherapy. Int. J. Cancer 135, 26972710 (2014).

4. Sato, K., Choyke, P. L. \& Kobayashi, H. Photoimmunotherapy of gastric cancer peritoneal carcinomatosis in a mouse model. PLoS One 9, e113276 (2014).

5. Nagaya, T. et al. Near infrared photoimmunotherapy with avelumab, an antiprogrammed death-ligand 1 (PD-L1) antibody. Oncotarget 8, 8807-8817 (2017).

6. Nagaya, T. et al. Near-Infrared Photoimmunotherapy Targeting Prostate Cancer with Prostate-Specific Membrane Antigen (PSMA) Antibody. Mol. Cancer Res. 15, 1153 1162 (2017)

7. Nagaya, T. et al. Near Infrared Photoimmunotherapy Targeting EGFR Positive Triple Negative Breast Cancer: Optimizing the Conjugate-Light Regimen. PLoS One 10 (2015). 
373 8. Takakura, H. et al. Analysis of the triplet-state kinetics of a photosensitizer for 374 photoimmunotherapy by fluorescence correlation spectroscopy. J. Photochem. and Photobiol. A: Chem. 408, 113094 (2021).

9. Kobayashi, M. et al. Theoretical and Experimental Studies on the Near-Infrared

10. Sato, K. et al. Photoinduced Ligand Release from a Silicon Phthalocyanine Dye Conjugated with Monoclonal Antibodies: A Mechanism of Cancer Cell Cytotoxicity after Near-Infrared Photoimmunotherapy. ACS Cent. Sci. 4, 1559-1569 (2018).

11. Ogawa, M. et al. Immunogenic cancer cell death selectively induced by near infrared photoimmunotherapy initiates host tumor immunity. Oncotarget 8, 10425-10436 (2017).

12. Nakajima, K., Takakura, H., Shimizu, Y. \& Ogawa, M. Changes in plasma membrane damage inducing cell death after treatment with near-infrared photoimmunotherapy. Cancer Sci. 109, 2889-2896 (2018).

13. Anderson, E. D., Sova, S., Ivanic, J., Kelly, L. \& Schnermann, M. J. Defining the conditional basis of silicon phthalocyanine near-IR ligand exchange. 
PhysChemChemPhys 20, 19030-19036 (2018).

14. Anderson, E. D., Gorka, A. P. \& Schnermann, M. J. Near-infrared uncaging or photosensitizing dictated by oxygen tension. Nat. Commun. 7, 13378 (2016).

15. Cleland, W. W. Dithiothreitol, a New Protective Reagent for Sh Groups. Biochemistry 3, 480-482 (1964).

16. Inaba, K. \& Ito, K. Paradoxical redox properties of DsbB and DsbA in the protein disulfide-introducing reaction cascade. EMBO J. 21, 2646-2654 (2002).

17. Berg, J. M., Tymoczko, J. L. \& Stryer, L. Biochemistry (W.H. Freeman and Co. ; [Palgrave], 2002).

18. Zhu, X. H., Lu, M., Lee, B. Y., Ugurbil, K. \& Chen, W. In vivo NAD assay reveals dependences. Proc. Natl. Acad. Sci. USA 112, 2876-2881 (2015).

19. Jocelyn, P. C. The standard redox potential of cysteine-cystine from the thiol327-331 (1967).

20. Aslund, F., Berndt, K. D. \& Holmgren, A. Redox potentials of glutaredoxins and other protein-protein redox equilibria. J. Biol. Chem. 272, 30780-30786 (1997). 
21. Matsui, T., Kitagawa, Y., Okumura, M. \& Shigeta, Y. Accurate standard hydrogen electrode potential and applications to the redox potentials of vitamin $\mathrm{C}$ and NAD/NADH. $J$. Phys. Chem. $A 119$ (2015).

22. Lovander, M. D. et al. Critical Review-Electrochemical Properties of 13 Vitamins: A Critical Review and Assessment. J. Electrochem. Soc. 165, G18-G49 (2018).

23. Davison, J. B. \& Wynne, K. J. Silicon Phthalocyanine-Siloxane Polymers: Synthesis and 1H Nuclear Magnetic Resonance Study. Macromolecules 11, 186-191 (1978).

24. Gaussian 16 Rev. C.01 (Wallingford, CT, 2016).

25. Iikura, H., Tsuneda, T., Yanai, T. \& Hirao, K. A long-range correction scheme for

26. Becke, A. D. Density-functional exchange-energy approximation with correct asymptotic behavior. Phys. Rev. A Gen. Phys. 38, 3098-3100 (1988).

27. Lee, C., Yang, W. \& Parr, R. G. Development of the Colle-Salvetti correlation-energy

28. Kendall, R. A., Dunning, T. H. \& Harrison, R. J. Electron affinities of the first-row atoms revisited. Systematic basis sets and wave functions. J. Chem. Phys. 96, 6796- 

$6806(1992)$

29. Dunning, T. H. Gaussian basis sets for use in correlated molecular calculations. I. The atoms boron through neon and hydrogen. J. Chem. Phys. 90, 1007-1023 (1989).

30. Woon, D. E. \& Dunning, T. H. Gaussian basis sets for use in correlated molecular calculations. III. The atoms aluminum through argon. J. Chem. Phys. 98, 1358-1371 (1993).

31. Mennucci, B., Cancès, E. \& Tomasi, J. Evaluation of Solvent Effects in Isotropic and Anisotropic Dielectrics and in Ionic Solutions with a Unified Integral Equation Method: Theoretical Bases, Computational Implementation, and Numerical Applications. J. Phys. Chem. B 101, 10506-10517 (1997). 
(a)
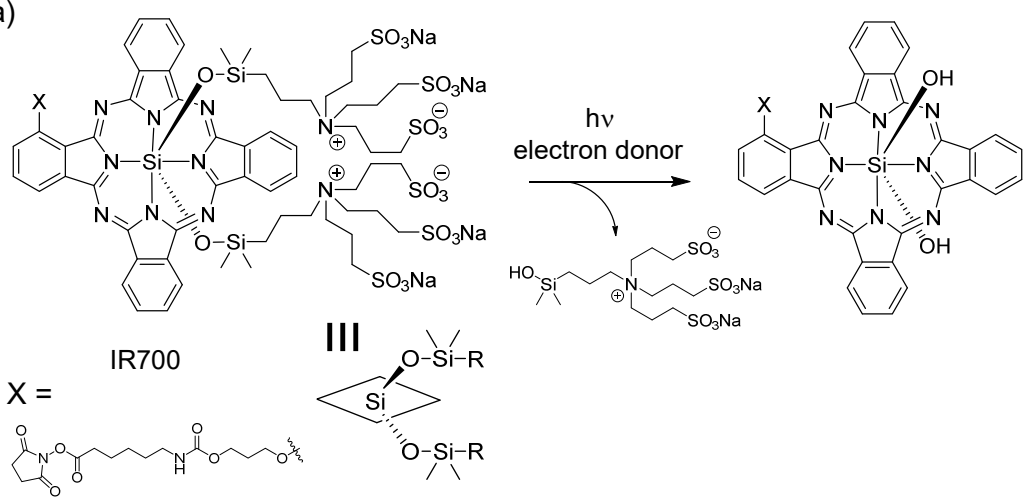

(b)

Fig. 1 Photochemical reaction in photoimmunotherapy (a) Axial ligand cleavage of

IRDye700DX (IR700), a photosensitizer for photoimmunotherapy. Cleavage is induced

by NIR light in the presence of an electron donor, and the hydrophobic compound is generated by loss of the hydrophilic axial ligands. (b) Plausible mechanism of axial ligand cleavage of IR700. Upon absorbance of excitation light, IR700 is excited to the singlet state. Some of the singlet state are transferred to the triplet state, resulting in generation of an anion radical by electron transfer from an electron donor. Next, stepwise reaction of the axial ligand involving water, such as protonation and ligand exchange, occur spontaneously. Finally, IR700 derivatives with the axial ligand cleaved are generated. 
(a)
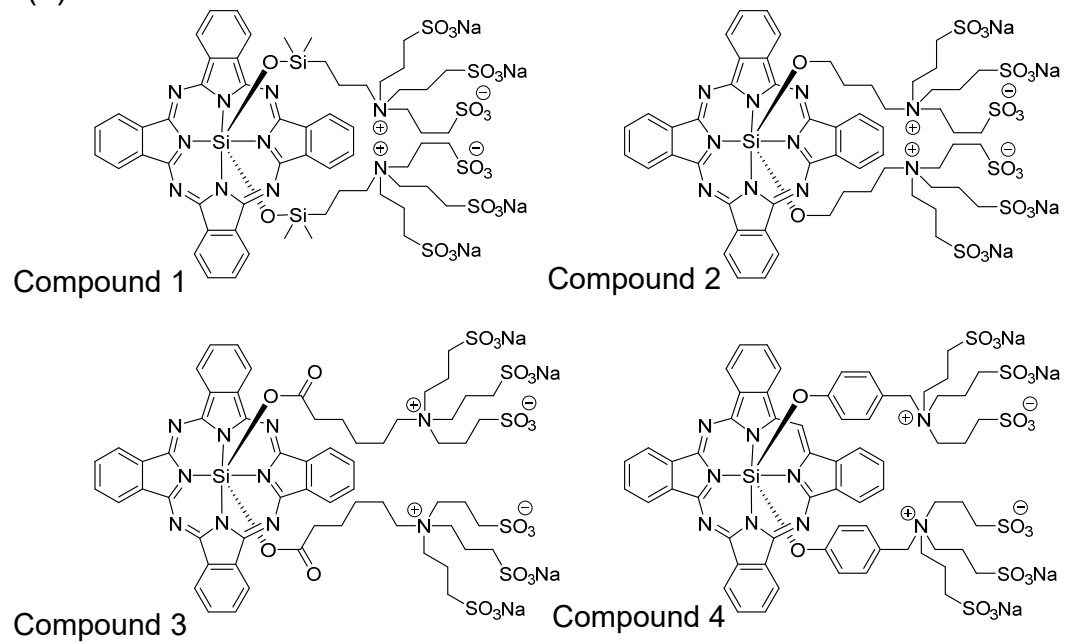

(b)

\begin{tabular}{ccccc}
{$\left[\mathrm{SiPcY}_{2}\right]^{--}+\mathrm{H}_{3} \mathrm{O}^{+} \stackrel{\Delta G}{\rightarrow}\left[\mathrm{SiPc}(\mathrm{YH}) \mathrm{Y}^{\bullet}+\mathrm{H}_{2} \mathrm{O}\right.$} \\
\hline $\begin{array}{c}\text { Compound } \\
\mathrm{Y}=\end{array}$ & $1^{\prime}$ & $2^{\prime}$ & $3^{\prime}$ & $4^{\prime}$ \\
\hline$\Delta G(\mathrm{KJ} / \mathrm{mol})$ & -143.0 & -147.6 & -103.5 & -106.8
\end{tabular}

Fig. 2 Computational calculation of silicon phthalocyanines with different axial

467 ligands (a) Structures of compounds 1-4. (b) Calculated $\Delta G$ (at $298.15 \mathrm{~K}, 1 \mathrm{~atm}$ ) of protonation to the oxygen atom on the Si-O bond (ULC-BLYP/cc-pVDZ, diffuse functions were augmented to $\mathrm{N}$ and $\mathrm{O}$ atoms, in water solvent). 

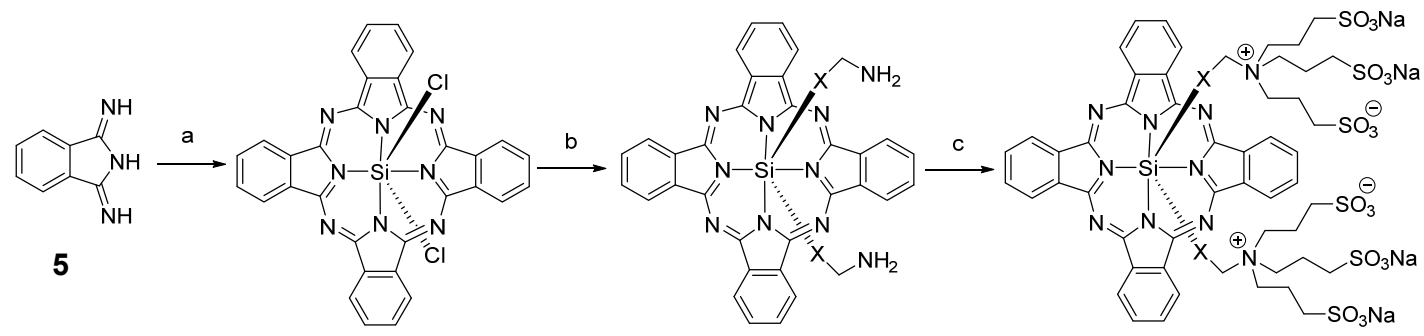

478

6

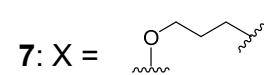

2: $X=\mathrm{O}^{\mathrm{s}}$

478

479

8: $X=$ o $^{1}$

$3: X=\overbrace{}^{3}$

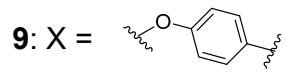

4: $\mathrm{X}=\operatorname{mon}^{0}$

Fig. 3 Synthetic scheme for compounds 2-4. (a) $\mathrm{SiCl}_{4}$, quinoline, (b) appropriate amines,

$\mathrm{NaH}$ or $\mathrm{K}_{2} \mathrm{CO}_{3}$, toluene, (c) sultone, $i \operatorname{Pr}_{2} \mathrm{EtN}, \mathrm{MeOH}$.

482

483

484

485

486

487

488

489

490

491

492 
(e)
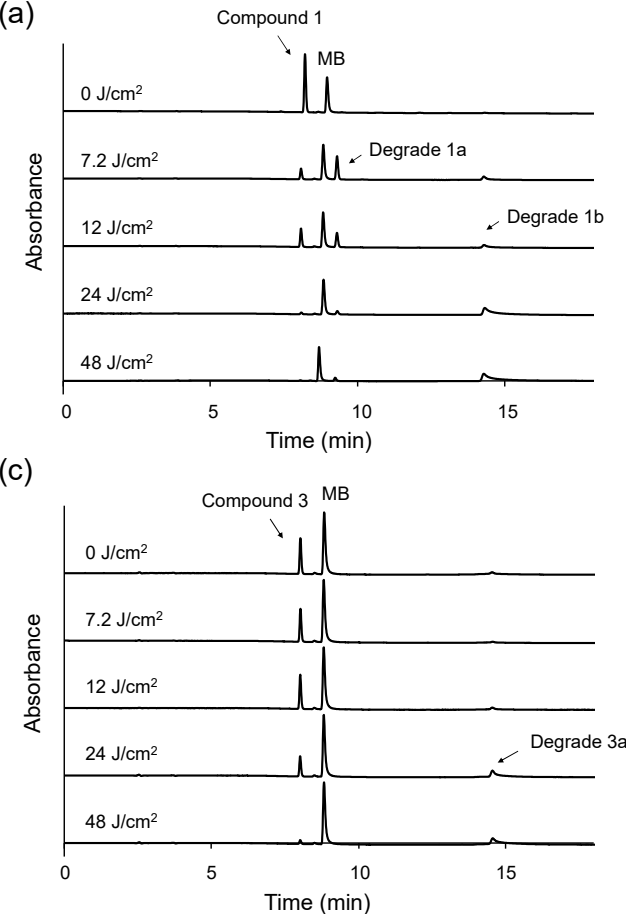

(c)

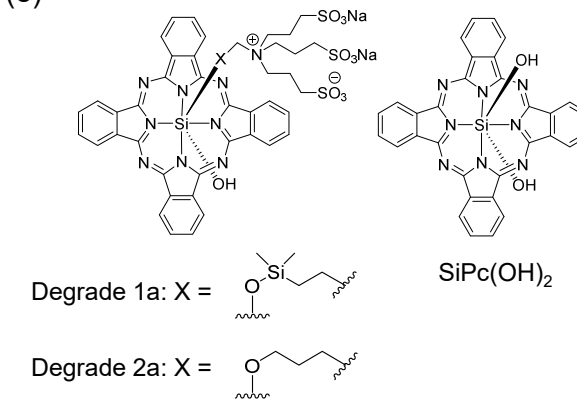

(b)

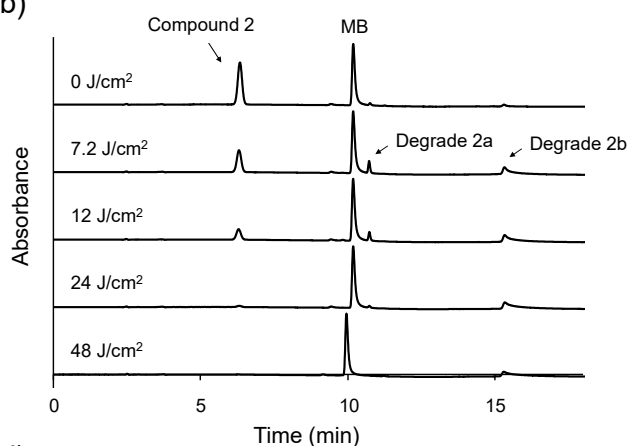

(d)

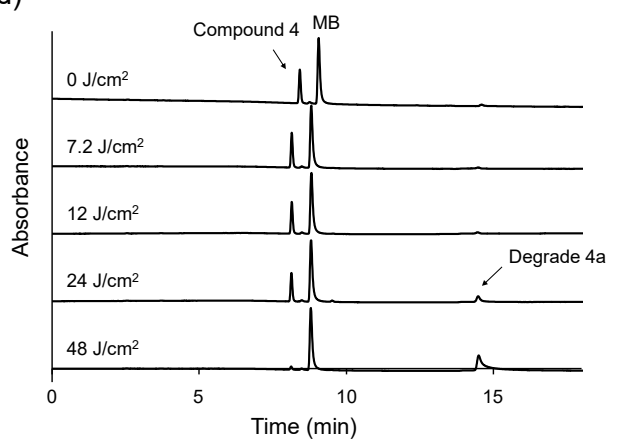

(f)

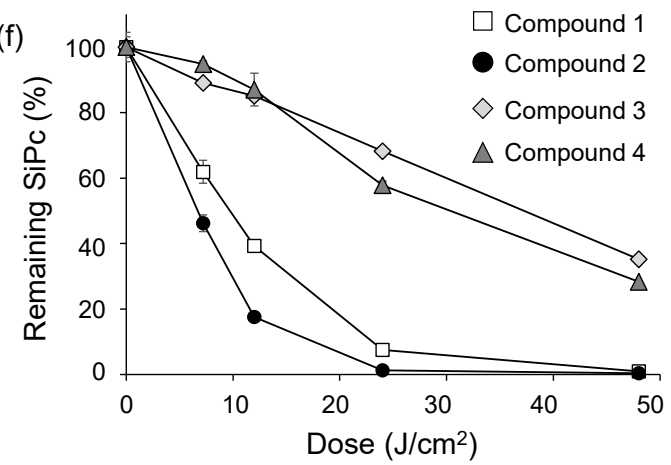

Fig. 4. HPLC analysis of photolysis by NIR light. Compounds 1-4 in the deoxygenated solution with $1 \mathrm{mM}$ DTT were irradiated by NIR light $(690 \mathrm{~nm})$ for the indicated times and the solution was analyzed by HPLC with methylene blue (MB) as an internal standard. (a) compound 1, (b) compound 2, (c) compound 3 and (d) compound 4. (e) Chemical structures of the degradation products after photolysis. (f) The ratio of absorbance peak

510 area compared to the sample before irradiation. Data represents the mean $\pm \operatorname{SEM}(n=3)$. 
512 Table 1. Absorbance/emission wavelengths $\left(\boldsymbol{\lambda}_{\text {abs }} / \lambda_{\mathrm{em}}\right)$, molar extinction coefficient $(\varepsilon)$

513 and fluorescence quantum yields $\left(\Phi_{\mathrm{FL}}\right)$ of compounds 1-4.

514

\begin{tabular}{|c|c|c|c|c|c|}
\hline \multirow[b]{2}{*}{ Compound } & \multirow{2}{*}{$\lambda_{\text {abs }} / \mathrm{nm}^{\mathrm{a}}$} & \multirow{2}{*}{$\lambda_{\mathrm{em}} / \mathrm{nm}^{\mathrm{a}}$} & \multicolumn{2}{|c|}{$\varepsilon \times 10^{5} / \mathrm{L} \mathrm{mol}^{-1} \mathrm{~cm}^{-1}$} & \multirow[b]{2}{*}{$\Phi_{\mathrm{FL}}$} \\
\hline & & & $\mathrm{H}_{2} \mathrm{O}$ & DMSO & \\
\hline 1 & 677 & 684 & 1.9 & 2.4 & $0.31^{\mathrm{b}}$ \\
\hline 2 & 684 & 690 & 1.7 & 2.0 & 0.30 \\
\hline 3 & 691 & 699 & 1.9 & 2.5 & 0.27 \\
\hline 4 & 689 & 695 & 1.7 & 2.0 & 0.29 \\
\hline
\end{tabular}

515

$516{ }^{a}$ Absorption/emission wavelengths were obtained from Fig. S2. ${ }^{b}$ Ref 8.

517

518

519 


\section{Supplementary Files}

This is a list of supplementary files associated with this preprint. Click to download.

- SupportingInformationNIRCommunChem.pdf 